Cite this: Chem. Commun., 2011, 47, 7152-7154

\section{Cooperative spin transition in a lipid layer like system $†$}

\author{
Received 14th April 2011, Accepted 9th May 2011 \\ DOI: $10.1039 / \mathrm{clcc12162f}$

\begin{abstract}
A novel iron(II) mononuclear spin transition complex [FeL(py) $\left.)_{2}\right]$ displays an abrupt spin transition around $225 \mathrm{~K}$ accompanied by a very wide thermal hysteresis loop $(\sim 50 \mathrm{~K})$ that spreads out over $100 \mathrm{~K}$. Crystal structure analysis in both low-spin and high-spin states reveals a lipid layer-like arrangement of the complex
\end{abstract} \\ molecules and provides insights into the spin switching mechanism.
}

Stephan Schlamp, ${ }^{a}$ Birgit Weber, ${ }^{* a}$ Anil D. Naik ${ }^{b}$ and Yann Garcia ${ }^{* b}$

Since the discovery of spin crossover (SCO) compounds in 1931 by Cambi et al. ${ }^{1}$ the interest in this substance class never vanished, ${ }^{2}$ as the thermochromism associated with the spin state change makes them potentially useful for various applications such as display and memory device units, ${ }^{3}$ sensors ${ }^{4}$ and cold channel control units in food and medical sectors. ${ }^{5}$ In order to realise application it is important to explore different possibilities for the nanostructuration of SCO materials ${ }^{6}$ and to investigate if additional properties can be combined (e.g. liquid crystal behaviour, ${ }^{7}$ magnetic exchange interactions ${ }^{8}$ ) resulting in multifunctional SCO materials. ${ }^{9}$ In this frame, we modified Schiff base like ligands used for the synthesis of SCO complexes ${ }^{10}$ by adding long alkyl chains in the outer periphery by preparing $\left[\mathrm{FeL}(\mathrm{py})_{2}\right]$ (1) with $\mathrm{L}=(E, E)$-[diethyl-2,2'-[4,5-dihexadecyloxy-1,2-phenylenebis(iminomethylidyne)]bis(3-oxobutanato)]. We aimed to study the influence of this modification on the crystal packing as well as on the SCO behaviour and investigate if additional features could be achieved for $\mathbf{1}$.

A complete description of the synthesis of $\mathrm{H}_{2} \mathrm{~L}$ and the iron complex (1) is given in the ESI. $\uparrow$ Single crystals suitable for an $\mathrm{X}$-ray analysis of $\mathbf{1} \cdot 0.25 \mathrm{H}_{2} \mathrm{O}$ were obtained and the crystal structure was determined first at $250 \mathrm{~K}$ and then at $125 \mathrm{~K}$ (same crystal, in both cases space group $P \overline{1}$ ), corresponding to the high-spin (HS) and low-spin (LS) states of the complex as seen in the magnetic measurement (Fig. 3). The crystallographic data are summarized in the ESI $\dagger$, Table S1. Fig. 1 displays an ORTEP drawing of the asymmetric unit of $\mathbf{1}$ in the HS and the LS state. An excerpt of the coordination

\footnotetext{
${ }^{a}$ Inorganic Chemistry II, Universität Bayreuth, Universitätsstraße 30, NW 1, 95440 Bayreuth, Germany. E-mail: weber@uni-bayreuth.de; Fax: + 49-92155-2157; Tel: + 49-92155-2555

${ }^{b}$ Institute of Condensed Matter and Nanosciences, MOST-Inorganic Chemistry, Université Catholique de Louvain, Place L. Pasteur 1, 1348 Louvain-la-Neuve, Belgium.

E-mail: yann.garcia@uclouvain.be; Fax: +32 10472831;

Tel: +3210472826

$\dagger$ Electronic supplementary information (ESI) available: Experimental details and spectroscopic analysis. CCDC 821515 and 821516. For ESI and crystallographic data in CIF or other electronic format see DOI: $10.1039 / \mathrm{clcc} 12162 \mathrm{f}$
}
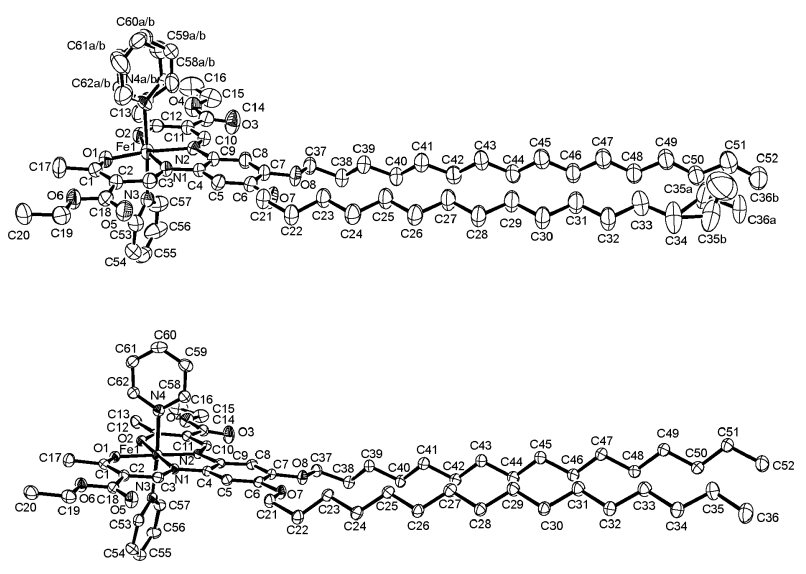

Fig. 1 ORTEP drawing of the asymmetric unit of 1 in the HS (top) and LS (bottom) states. Hydrogen atoms and the water molecule have been omitted for clarity. Displacement ellipsoids are shown at the $50 \%$ probability level.

Table 1 Selected bond lengths $[\AA]$ and angles $\left[{ }^{\circ}\right]$ within the inner coordination sphere of $\mathbf{1}$ in the HS and LS states

\begin{tabular}{lllllll}
\hline & $\mathrm{Fe}-\mathrm{N}_{\mathrm{eq}}$ & $\mathrm{Fe}-\mathrm{O}_{\mathrm{eq}}$ & $\mathrm{Fe}-\mathrm{N}\left(\mathrm{L}_{\mathrm{ax}}\right)$ & $\mathrm{O}-\mathrm{Fe}-\mathrm{O}$ & $\mathrm{L}_{\mathrm{ax}}-\mathrm{Fe}-\mathrm{L}_{\mathrm{ax}}$ & $\angle \mathrm{L}_{\mathrm{ax}}{ }^{b}$ \\
\hline HS & $2.059(3)$ & $2.001(2)$ & $2.284(3)$ & $106.10(9)$ & $173.73(12)^{a}$ & \\
& $2.086(2)$ & $1.999(2)$ & $2.280(4)^{a}$ & & $176.95(23)^{a}$ & $21.5^{a}$ \\
& & & $2.288(7)^{a}$ & & & $47.5^{a}$ \\
$\mathrm{LS}$ & $1.897(2)$ & $1.935(2)$ & $2.021(2)$ & $88.80(7)$ & $175.06(8)$ & 83.6 \\
& $1.907(2)$ & $1.947(2)$ & $2.014(2)$ & & & \\
\multicolumn{5}{c}{${ }^{a}$ Disorder. ${ }^{b}$ Angle between the pyridine planes. } \\
\hline
\end{tabular}

environment is given in Fig. S1 (ESI $\dagger$ ). Selected bond lengths and angles around the inner coordination sphere of the iron centre are summarized in Table 1.

The average bond lengths within the first coordination sphere of the iron(II) centres in the HS structure are $2.07 \AA\left(\mathrm{Fe}-\mathrm{N}_{\mathrm{eq}}\right)$, $2.00 \AA\left(\mathrm{Fe}-\mathrm{O}_{\mathrm{eq}}\right)$ and $2.28 \AA\left(\mathrm{Fe}-\mathrm{L}_{\mathrm{ax}}\right)$. Those and the observed $\mathrm{O}-\mathrm{Fe}-\mathrm{O}$ angle $\left(106^{\circ}\right)$ are in the region expected for HS complexes of this ligand type. ${ }^{10,11}$ Upon the HS to LS transition a shortening of the bond lengths of about $10 \%$ is observed, as observed for other iron(II) SCO complexes. ${ }^{2,11}$ The average bond lengths in the LS-structure are $1.90 \AA\left(\mathrm{Fe}-\mathrm{N}_{\text {eq }}\right), 1.94 \AA\left(\mathrm{Fe}-\mathrm{O}_{\text {eq }}\right)$ and $2.02 \AA$ $\left(\mathrm{Fe}-\mathrm{L}_{\mathrm{ax}}\right)$ with an $\mathrm{O}-\mathrm{Fe}-\mathrm{O}$ angle of $89^{\circ}$. In the $\mathrm{HS}$ state, a disorder is observed of one pyridine and at the end of one of the $\mathrm{C}^{16}$ alkyl chains. The pyridine ring including $\mathrm{N} 4$ is contorted in two directions in a relative ratio of $60: 40$, the same ratio is observed for the ethyl endgroup (C35 and C36) in the alkyl chain bound by O7. The planes spanned by the two axial pyridine rings are 


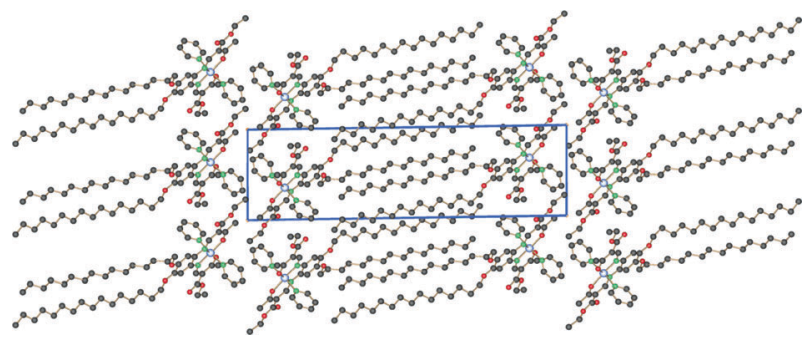

Fig. 2 Packing of the molecules of $\mathbf{1} \cdot 0.25 \mathrm{H}_{2} \mathrm{O}$ in the crystal projected along $\left[\begin{array}{lll}1 & 0 & 0\end{array}\right]$ in the HS state.

staggered in the HS state. Upon cooling the disordered pyridine ring changes its orientation resulting in a nearly perpendicular arrangement in the LS state. An additional water molecule is observed in the crystal packing with an approximate occupation number of 0.25 . Several hydrogen bonds and short contacts are observed between the complex molecules and the water (Table S2, ESI $\dagger$ ).

In the crystal the molecules are packed in a lipid layer like arrangement as illustrated in Fig. 2 with the layers running along the $a$ - $b$-plane. Within one layer, the alkyl chains of the Schiff base like ligand are packed in the middle and the SCO centres are on the outer sides.

In the LS state a network of hydrogen bonds is formed between the SCO centres between the layers and within the layer, the additional water molecule being also involved, as illustrated in Fig. S2 (ESI $\dagger$ ). In the HS state the rearrangement of the pyridine ring and the alkyl chain results in changes for the short contacts. Now, short contacts are only observed between the molecules of one lipid like layer but not between the layers as illustrated in Fig. S2 and S3 (ESI $\dagger$ ).

Magnetic susceptibility data of $\mathbf{1} \cdot 0.25 \mathrm{H}_{2} \mathrm{O}$ were recorded on cooling and warming over the temperature range $300-5 \mathrm{~K}$ (Fig. 3 ). At room temperature the $\chi_{\mathrm{M}} T$ product is $3.0 \mathrm{~cm}^{3} \mathrm{~K} \mathrm{~mol}^{-1}$ which is in the range expected for an iron(II) complex in the HS state. In the first cycle (squares) upon cooling the magnetic moment remains constant until $229 \mathrm{~K}$ where an abrupt spin transition (ST) takes place with about $60 \%$ of the molecules and $T_{\mathrm{c}}^{(60) \downarrow}=$ $222 \mathrm{~K}$. In the temperature range between $214 \mathrm{~K}$ and $185 \mathrm{~K}$ the magnetic moment decreases gradually from $\chi_{\mathrm{M}} T(214 \mathrm{~K})=$ $1.1 \mathrm{~cm}^{3} \mathrm{~K} \mathrm{~mol}^{-1}$ to $\chi_{\mathrm{M}} T(185 \mathrm{~K})=0.6 \mathrm{~cm}^{3} \mathrm{~K} \mathrm{~mol}^{-1}$. Below $185 \mathrm{~K}$ a second abrupt step is observed involving the remaining $20 \%$ of the molecules $T_{\mathrm{c}}^{(20) \downarrow}=182 \mathrm{~K}$. At $100 \mathrm{~K}$ the remaining $\chi_{\mathrm{M}} T$ product is $0.1 \mathrm{~cm}^{3} \mathrm{~K} \mathrm{~mol}^{-1}$ which is in the range expected for

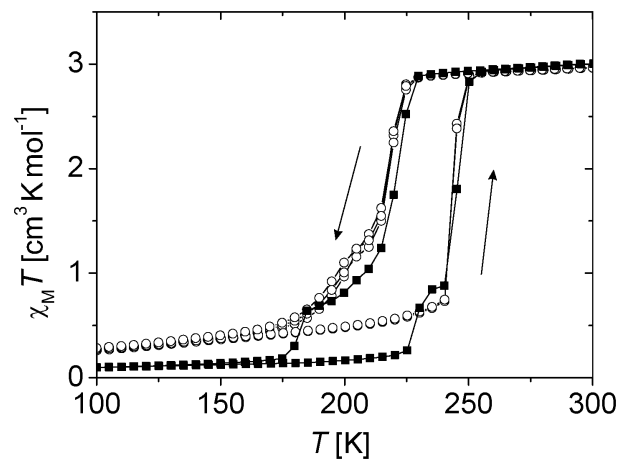

Fig. $3 \chi_{\mathrm{M}} T$ vs. $T$ plot of 1 of the first cycle (squares) and all the following cycles (open circles). Displayed in the temperature range 300-100 K. an iron(II) complex in the LS state. Upon heating the ST occurs in two steps with about $30 \%$ of the molecules involved in the first $\left(T_{\mathrm{c}}^{(30) \uparrow}=229 \mathrm{~K}\right)$ and about $70 \%$ of the molecules involved in the second step $\left(T_{\mathrm{c}}^{(70) \uparrow}=245 \mathrm{~K}\right)$. The width of the thermal hysteresis loop is $23 \mathrm{~K}$ for the first and $47 \mathrm{~K}$ for the second step. The second and third thermal cycles reveal the absence of the second gradual step and the remaining $\chi_{\mathrm{M}} T$ product is $0.3 \mathrm{~cm}^{3} \mathrm{~K} \mathrm{~mol}^{-1}$ at $100 \mathrm{~K}$ indicating an iron(II) complex almost completely in the LS state.

The sample has been studied by differential scanning calorimetry (DSC) over the temperature range 300-98 $\mathrm{K}$ in cooling and warming modes, at $10 \mathrm{~K} \mathrm{~min}^{-1}$, in order to extract thermodynamical parameters associated with the spin transition, and probe the order of the phase transitions. On warming from $98 \mathrm{~K}$, two major endothermic peaks corresponding to a first order phase transition proceeding in two steps were detected (Fig. 4). The first one is observed at $T_{\max }{ }^{(1) \uparrow}=235(1) \mathrm{K}$ and a broader peak is found at $T_{\max }{ }^{(2) \uparrow}=250(1) \mathrm{K}$. These data match the transition temperatures derived from SQUID measurements (see Fig. 3). A very less intense peak, whose shape indicates a continuous or weakly first-order phase transition, is observed at $T^{(3)}=240 \mathrm{~K}$ corresponding to the plateau region between the two phase transitions. On cooling from room temperature, broader exothermic peaks arise at different temperatures, confirming the hysteretic character of the ST process. A peak is found at $T_{\max }^{(2) \downarrow}=226(1) \mathrm{K}$, in agreement with the first ST branch, which is followed by a second peak at $T_{\max }{ }^{(1) \downarrow}=207(1) \mathrm{K}$, which only corresponds to the onset of the plateau region of the magnetic curve. The tiny second step in the cooling mode of the first cycle of the SQUID measurements around $182 \mathrm{~K}$ is not seen by DSC. Such a DSC profile was confirmed by two successive cooling and heating cycles. Interestingly, two peaks are still observed in the warming and cooling process after the first cycling. One is clearly related to the spin transition (2) whereas the other peak (1) relates to a thermal anomaly that plays a role in the spin state during the first cycle but not later, still existing but not affecting it. Enthalpy and entropy associated with these peaks are given in Table S3 $(\mathrm{ESI} \dagger)$.

This unprecedented ST behaviour can be explained thanks to the results from X-ray structure analysis. Step-wise spin transitions are often related to the presence of two or more inequivalent iron centres. ${ }^{12}$ In our case, the disorder of the pyridine ring in the HS state could be responsible for inequivalent iron centres and thus the steps in the transition curve. Such a

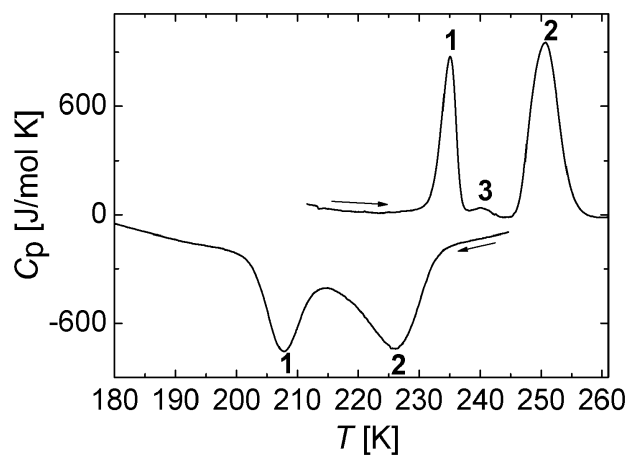

Fig. 4 Heat capacity $v s . T$ of 1 over the temperature range $261-180 \mathrm{~K}$ at a scanning rate of $10 \mathrm{~K} \mathrm{~min}^{-1}$ in the cooling $(\leftarrow)$ and warming $(\rightarrow)$ modes. 
situation was recently discussed by Matouzenko et al. ${ }^{13}$ with the same symmetries in the HS and LS states and a symmetry breaking on the plateau. ${ }^{14}$ As different intermolecular interactions are observed for the disordered parts of the HS state (Fig. S2, $\mathrm{ESI} \dagger$ ) the differences in the hysteresis width can be explained with differences in the H-bond network. It should be noted that the space group does not change upon ST and thus the observed hysteresis cannot be related to a structural phase transition but must be related to other cooperative effects. Due to the long alkyl chains in the outer periphery of the complex the observed change in the cell volume $(\Delta V / V=2.9 \%)$ is very small, especially when the contribution from the thermal contraction is considered. Thus the hysteresis cannot solely be related to elastic interactions. The changes in the hydrogen bond network are one possible explanation for the cooperative spin transition. ${ }^{15}$ A very interesting feature concerns the second peak in the DSC measurements that is related to the gradual part in the ST curve. This thermal anomaly could result from an order-disorder transition of the pyridine ring, ${ }^{16}$ which is disordered in the HS state and that orders in the LS, as detected by X-ray diffraction. Such types of transitions are known to be able to control the course of a ST leading to gradual regions. ${ }^{17}$ The disappearance of the small step after the first cooling/heating cycle could be related to small changes in the molecule structure or the intermolecular interactions due to this order-disorder transition.

The introduction of long alkyl chains in the outer periphery of Schiff base like ligands did lead to head-tail molecules that crystallise in a lipid layer like structure and show a cooperative spin transition with a wide thermal hysteresis loop (up to $\sim 50 \mathrm{~K}$ ). The X-ray structure solved in the HS and LS states allows a deeper insight into the ST mechanism of $\mathbf{1}$ which results from an interplay involving the H-bond network and order-disorder transition of the pyridine rings.

We thank S. Albrecht and P. Mayer (University of Munich) for the collection of the X-ray data and P. Thoma (University of Bayreuth) for the collection of the NMR data. Support from the University of Bayreuth, the Deutsche Forschungsgemeinschaft (WE 3546_4-1), the Fonds der Chemischen Industrie, the IAP-VI (P6/17) INANOMAT, FNRS (FRFC 2.4508.08) and ARC-Académie Louvain is gratefully acknowledged.

\section{Notes and references}

1 (a) L. Cambi and L. Szegö, Ber. Dtsch. Chem. Ges. A, 1931, 64, 167; (b) L. Cambi and L. Malatesta, Ber. Dtsch. Chem. Ges. B, 1937, 70, 2067.

2 (a) H. A. Goodwin, Coord. Chem. Rev., 1976, 18, 293; (b) E. König, Struct. Bonding, 1991, 76, 51; (c) P. Gütlich, A. Hauser and H. Spiering, Angew. Chem., Int. Ed. Engl., 1994, 33, 2024 and references therein; (d) "Spin Crossover in Transition Metal Compounds I-III", ed. P. Gütlich and H. A. Goodwin, Topics in Current Chemistry, Springer-Verlag Berlin Heidelberg, New York, 2004; (e) J. A. Real, A. B. Gaspar and M. C. Munoz, Dalton Trans., 2005, 2062; (f) K. Nakano, N. Suemura, K. Yoneda, S. Kawata and S. Kaizaki, Dalton Trans., 2005, 740; ( $g$ ) O. Sato, J. Tao and Y.-Z. Zhang, Angew. Chem., 2007, 119, 2200 (Angew. Chem., Int. Ed., 2007, 46, 2152); (h) J. A. Kitchen and S. Brooker, Coord. Chem. Rev., 2008, 252, 2072; (i) K. S. Murray, Eur. J. Inorg. Chem., 2008, 3101; (j) M. A. Halcrow, Coord. Chem. Rev., 2009, 253, 2493-2514; (k) S. Brooker and J. A. Kitchen, Dalton Trans., 2009, 7331; (l) C. J. Kepert, Aust. J. Chem., 2009, 62, 1079; (m) K. S. Murray, Aust. J. Chem., 2009, 62, 1081; (n) A. B. Koudriavtsev and W. Linert, J. Struct. Chem., 2010, 51, 335.
3 (a) O. Kahn and C. J. Martinez, Science, 1998, 279, 44; (b) O. Kahn, C. Jay, J. Kröber, R. Claude and F. Grolière, Patent, EP06665611995; (c) J.-F. Létard, O. Nguyen and N. Daro, Patent, FR05124762005; (d) J.-F. Létard, P. Guionneau and L. Goux-Capes, in Topics in Current Chemistry, ed. P. Gütlich et and H. A. Goodwin, Springer WienNew York, 2004, vol. 235, p. 221; (e) A. Galet, A. B. Gaspar, M. C. Munoz, G. V. Bukin, G. Levchenko and J. A. Real, $A d v$. Mater., 2005, 17, 2949.

4 Y. Garcia, V. Ksenofontov and P. Gütlich, Hyperfine Interact., 2002, 139-140, 543

5 Y. Garcia, V. Ksenofontov, S. Mentior, M. M. Dîrtu, C. Gieck, A. Bhatthacharjee and P. Gütlich, Chem.-Eur. J., 2008, 14, 3745.

6 (a) I. Boldog, A. B. Gaspar, V. Martinez, P. Pardo-Ibanez, V. Ksenofontov, A. Bhattacharjee, P. Gütlich and J. A. Real, Angew. Chem., Int. Ed., 2008, 47, 6433-6437; (b) S. Cobo, G. Molnar, J. A. Real and A. Bousseksou, Angew. Chem., Int. Ed., 2006, 45, 5786-5789; (c) G. Molnár, S. Cobo, J. A. Real, F. Carcenac, E. Daran, C. Vieu and A. Bousseksou, Adv. Mater., 2007, 19, 2163; (d) M. Cavallini, I. Bergenti, S. Milita, G. Ruani, I. Salitros, Z.-R. Qu, R. Chandrasekar and M. Ruben, Angew. Chem., Int. Ed., 2008, 47, 8596; (e) A. D. Naik, L. Stappers, J. Snauwaert, J. Fransaer and Y. Garcia, Small, 2010, 6, 2842 .

7 (a) M. Seredyuk, A. B. Gaspar, V. Ksenofontov, Y. Galyametdinov, M. Verdaguer, F. Villain and P. Gütlich, Inorg. Chem., 2008, 47, 10232-10245; (b) M. Seredyuk, A. B. Gaspar, V. Ksenofontov, Y. Galyametdinov, J. Kusz and P. Gütlich, Adv. Funct. Mater. 2008, 18, 2089; (c) M. Seredyuk, A. B. Gaspar, V. Ksenofontov, Y. Galyametdinov, J. Kusz and P. Gütlich, J. Am. Chem. Soc., 2008, 130, 1431.

8 (a) J. A. Real, A. B. Gaspar, V. Niel and M. C. Muñoz, Coord. Chem. Rev., 2003, 236, 121; (b) A. Bousseksou, G. Molnár, J. A. Real and K. Tanaka, Coord. Chem. Rev., 2007, 251, 1822-1833.

9 (a) A. B. Gaspar, V. Ksenofontov, M. Seredyuk and P. Gütlich, Coord. Chem. Rev., 2005, 249, 2661-2676; (b) A. B. Gaspar, M. Seredyuk and P. Gütlich, J. Mol. Struct., 2009, 924-926, 9-19.

10 (a) B. Weber, Coord. Chem. Rev., 2009, 253, 2432; (b) B. Weber and E.-G. Jäger, Eur. J. Inorg. Chem., 2009, 465.

11 (a) B. Weber, E. Kaps, J. Weigand, C. Carbonera, J.-F. Letard, K. Achterhold and F. Parak, Inorg. Chem., 2008, 47, 487; (b) B. Weber, J. Obel, D. Henner-Vásquez and W. Bauer, Eur. J. Inorg. Chem., 2009, 5527.

12 (a) Y. Garcia, O. Kahn, L. Rabardel, B. Chansou, L. Salmon and J.-P. Tuchagues, Inorg. Chem., 1999, 38, 4663; (b) G. S. Matouzenko, J.-F. Letard, S. Lecocq, A. Bousseksou, L. Capes, L. Salmon, M. Perrin, O. Kahn and A. Collet, Eur. J. Inorg. Chem., 2001, 2935; (c) W. Hibbs, P. J. van Koningsbruggen, A. M. Arif, W. W. Shum and J. S. Miller, Inorg. Chem., 2003, 42, 5645; (d) P. Poganiuch, S. Decurtins and P. Gütlich, J. Am. Chem. Soc., 1990, 112, 3270; (e) L. Wiehl, Acta Crystallogr., Sect. B: Struct. Sci., 1993, 49, 289; (f) R. Hinek, H. Spiering, D. Schollmeyer, P. Gütlich and A. Hauser, Chem.-Eur. J., 1996, 2, 1427; ( $g$ ) B. Weber, C. Carbonera, C. Desplanches and J.-F. Létard, Eur. J. Inorg. Chem., 2008, 1589; (h) B. Li, R.-J. Wei, R.-B. Huang, L.-S. Zheng and Z. Zheng, J. Am. Chem. Soc., 2010, 132, 1558-1566; (i) R.-J. Wei, J. Tao, R.-B. Huang, L.-S. Zheng and Z. Zheng, Inorg. Chem., 2011, 50, 1170-1172.

13 G. S. Matouzenko, D. Luneau, G. Molnár, N. Ould-Moussa, S. Zein, S. A. Borshch, A. Bousseksou and F. Averseng, Eur. J. Inorg. Chem., 2006, 2671-2682.

14 M. B.-L. Cointe, N. O. Moussa, E. Trzop, A. Moréac, G. Molnar, L. Toupet, A. Bousseksou, J. F. Létard and G. S. Matouzenko, Phys. Rev. B, 2010, 82, 214106.

15 (a) B. Weber, W. Bauer and J. Obel, Angew. Chem., 2008, 120, 10252 (Angew. Chem., Int. Ed., 2008, 47, 10098-10101); (b) B. Weber, W. Bauer, T. Pfaffeneder, M. M. Dîrtu, A. D. Naik, A. Rotaru and Y. Garcia, Eur. J. Inorg. Chem., 2011, in press.

16 (a) I. Szafraniak and P. Czarnecki, J. Phys.: Condens. Matter, 2002, 14, 3321; (b) D. Vujosevic, K. Mulller and E. Roduner, J. Phys. Chem. B, 2006, 110, 8598.

17 (a) V. A. Money, J. Elhaik, I. R. Evans, M. A. Halcrow and J. A. K. Howard, Dalton Trans., 2004, 65-69; (b) B. Weber, E. S. Kaps, J. Obel, K. Achterhold and F. G. Parak, Inorg. Chem., 2008, 47, 10779 . 